\title{
Studying the Level of Angiotensin II in Various Areas of Jordan with Different Altitudes
}

\author{
Reema Kamal Haddad \\ Jehan Fayez Sweis \\ Dafer Haddadin \\ Ramzi Abdallah Aldalabih \\ Raya Mohammed Aladaileh \\ Jaafar Abu Abeeleh \\ Royal Medical Services, Jordan \\ Mahmoud Abu Abeeleh \\ The University of Jordan, Jordan \\ Mustafa Ahmad Al-Shehabat
}

Department of physiology, Faculty of Medicine, Jordan University of

Science and technology, Jordan

Ahed J Alkhatib

Jordan University of Science and technology, Jordan

\begin{abstract}
Background and objectives: angiotensin II is involved in the development of hypertension. The main objectives of the study were to measure and compare the levels of angiotensin II among normal population in various areas with different altitudes Methods: Study design: cross- sectional study was conducted to collect data from participants at the same time. Study setting: participants from various areas with different altitudes were recruited to participate in this study. A total of 1500 participants were included. Study procedure: data was collected from participants based on a questionnaire that was constructed for this study. Blood samples were withdrawn from participants by a well- trained nurse. Angiotensin II was measured using enzyme linked immune sorbent assay (ELISA). Statistical analysis: data was analyzed using SPSS version 20. Data was represented as means, standard deviations, frequencies and percentage. The relationship between variables was tested using independent T-Test. The significance was considered at $\mathrm{p}$ value $<0.05$. Results: the level of angiotensin II was $8.84 \pm 4.65 \mathrm{pg} / \mathrm{ml}$ in Dead Sea, $11.21 \pm 6.05 \mathrm{pg} / \mathrm{ml}$ in Sea level, and $12.08 \pm 5.19 \mathrm{pg} / \mathrm{ml}$ in Ajloun. There was a significant difference between the means of angiotensin II between
\end{abstract}


Ajloun and Dead Sea $(\mathrm{p}=0.039)$. no other significant differences were observed between the study areas. Conclusion: the angiotensin II varies between the areas according to their altitudes and this consideration should be taken into account when hypertensive drugs are prescribed.

Keywords: Angiotensin II, altitudes, the Dead Sea, Ajloun, Sea level.

\section{Introduction}

Angiotensin is an oligopeptide in the blood that causes vasoconstriction, increased blood pressure, and release of aldosterone from the adrenal cortex. It is derived from the precursor molecule angiotensinogen, a serum globulin produced in the liver and it plays an important role in the reninangiotensin-aldosterone system. Angiotensin was independently isolated in Indianapolis and Argentina in the late 1930s (as 'Angiotonin' and 'Hypertensin' respectively) and subsequently characterized and synthesized by groups at the Cleveland Clinic and Ciba laboratories in Basel, Switzerland (Basso and Terragno, 2001).

Angiotensinogen is an $\alpha$-2-globulin that is produced constitutively and released into the circulation mainly by the liver (Skurk et al, 2001). It is a member of the serpin (serine protease inhibitor)-family of proteins in blood interacts with and inhibits other enzymes of the blood coagulation system (Devlin, 2006), although it is not known to inhibit other enzymes, unlike most serpins. Plasma angiotensinogen levels are increased by plasma corticosteroid, estrogen, thyroid hormone, and angiotensin II levels. Angiotensinogen is also known as renin substrate. Human angiotensinogen is 452 amino acids long, but other species have angiotensinogen of varying sizes (Basso and Terragno, 2001).

Angiotensin I is formed by the action of renin on angiotensinogen. Renin cleaves the peptide bond between the leucine (Leu) and valine (Val) residues on angiotensinogen, creating the ten amino acid peptide, angiotensin I.

Angiotensin I appears to have no biological activity and exists solely as a precursor to angiotensin II (Carson et al., 1999). Angiotensin I is converted to angiotensin II through removal of two terminal residues by the enzyme Angiotensin-converting enzyme (ACE), which is found predominantly in the capillaries of the lungs (Skurk et al., 2001). ACE is actually found all over the body, but it has its highest density in the lung. Angiotensin II acts as an endocrine, autocrine/ paracrine, and intracrine hormone (Lees et al., 1993).

\section{Angiotensin II}

It is a potent direct vasoconstrictor that constricts arteries and veins and increases blood pressure by increasing blood volume and peripheral 
resistance (Ardaillou, 1997).It increases thirst sensation through the subfornical organ of the brain, decreases the response of the baroreceptor reflex, and increases the desire for salt. It increases secretion of ADH in the posterior pituitary and secretion of ACTH in the anterior pituitary. It also potentiates the release of norepinephrine by direct action on postganglionic sympathetic fibers (Berry et al., 2002).

Angiotensin II acts on the adrenal cortex, causing it to release aldosterone, a hormone that causes the kidneys to retain sodium and lose potassium (Hall, 2003).

Angiotensin II causes constriction of the efferent renal arterioles, which has two effects on peritubular capillary dynamics that raise sodium and water reabsorption. First, efferent arteriolar constriction reduces peritubular capillary hydrostatic pressure. Second, efferent arteriolar constriction reduces renal blood flow, raises filtration fraction in the glomerulus and increases the concentration of proteins and colloid osmotic pressure in the peritubular capillaries. This leads to an increase in the reabsorptive force at the peritubular capillaries and raises tubular reabsorption of sodium and water. Angiotensin II directly stimulates sodium reabsorption in the proximal tubules, in the loops of Henle, in the distal tubules, and in the collecting tubules (Guyton, Hall, 2006).

Parati et al (2014) studied the level of angiotensin II and blood pressure in high altitude areas taking into consideration that little information is available about ambulatory blood pressure (ABP) variations and the efficacy of antihypertensive drugs under such conditions. Moreover, the authors expressed their views that there is a deficiency of information about the efficacy of angiotensin receptor blockers under these condition. Findings of their study showed that both blood pressure and angiotensin II were increased with high altitudes and that the blockage of angiotensin receptor II helped in maintaining blood pressure.

Our study aimed to measure and compare the levels of angiotensin II among normal population in various areas with different attitudes.

\section{Methods and subjects Study design}

Cross sectional design was conducted in three areas: the Dead Sea (400 meters below the Sea level), the Sea level area and Ajloun area (1200 meters above the Sea level), Jordan.

The study sample included a total of 1500 participants of them 500 participants were included from each area. All participants were males, matched for age grouping, and they were apparently healthy. 


\section{Data collection}

The data for each participant was collected and tabulated. Data included study variables such as blood pressure, weight, height, waist circumference, heart rate per minute, the level of angiotensin II, and packed cell volume $(\mathrm{PCV})$.

\section{Study procedure}

The following measurements were taken: blood pressure for all participants was measured using sphygmomanometer with a stethoscope. Height was measured using 2 metric scaled rulers fixed to the wall of the room. Weight was measured using a well calibrated scale. Waist circumference was measured using a manual metric scale in centimeters. Heart rate was measured through radial pulse from the left hand for full minute, while the subjects were at rest. Angiotensin II was measured using enzyme linked immunosorbent assay (ELISA).

\section{Data analysis}

The analysis of data was carried out using SPSS version 20. All data were included and represented as mean and standard deviation. The relations between variables were computed using independent T test. Significance was considered at $\mathrm{p}$ value $<0.05$.

\section{Results}

\section{General characteristics of participants}

As seen in table 1, age was within the similar pattern in study areas in which it was 17.6 years in both Dead sea level and Sea level, and slightly higher in Ajloun (17.83 years). Weight $(\mathrm{kg})$ was also following similar distribution in study areas $(67.31 \mathrm{~kg}-67.69 \mathrm{~kg})$. The height $(\mathrm{cm})$ was also observed within similar patterns and this pattern was observed for the remaining variables included in table 1.

Table 1: General characteristics of participants

\begin{tabular}{|l|l|l|l|}
\hline variables & Dead sea level & Sea level & Ajloun \\
\hline Age & 17.6 & 17.6 & 17.83 \\
\hline Wt/kg & 67.31 & 67.69 & 67.37 \\
\hline Ht/cm & 169.29 & 170.5 & 169.51 \\
\hline BMI & 23.45 & 23.26 & 23.42 \\
\hline Waist/cm & 76.37 & 76.38 & 75.99 \\
\hline SBP/mmHg & 122.42 & 118.07 & 125.74 \\
\hline DBP/mmHg & 76.31 & 75.74 & 79.62 \\
\hline MBP/mmHg & 91.64 & 89.84 & 94.95 \\
\hline Pulse/min & 79.74 & 79.07 & 81.71 \\
\hline PCV & 42.17 & 41.50 & 45.27 \\
\hline
\end{tabular}




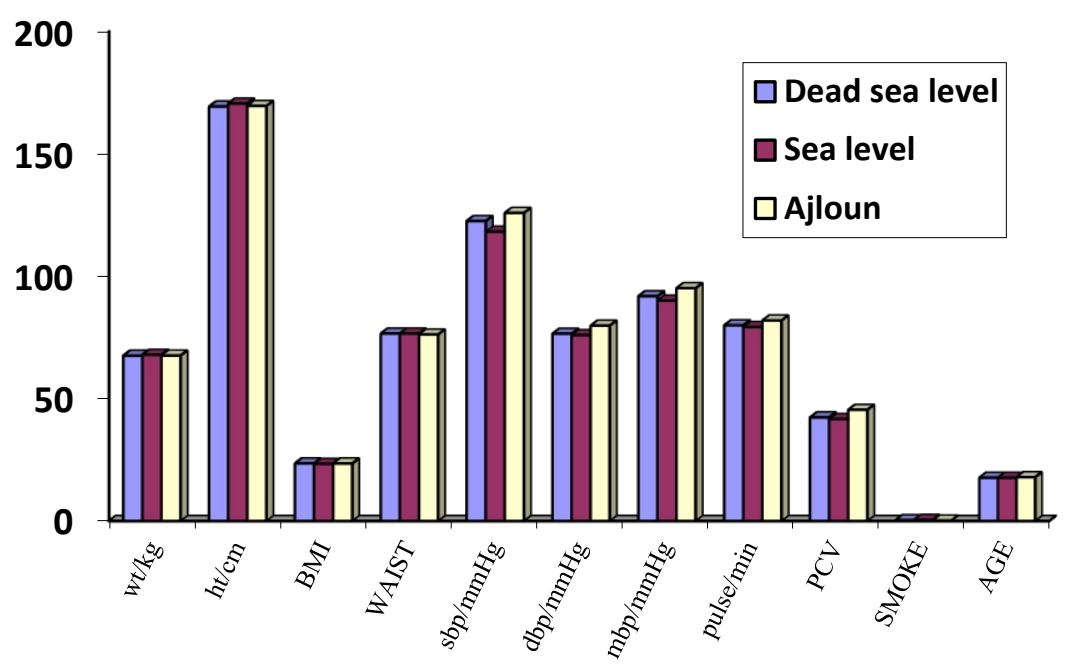

Figure1: Comparison between the means of variables Affecting Blood Pressure.

\section{The level of Angiotensin II in study areas}

As it can be seen in from table 2, the level of angiotensin II is $8.84 \pm$ $4.65 \mathrm{pg} / \mathrm{ml}$ in Dead Sea, $11.21 \pm 6.05 \mathrm{pg} / \mathrm{ml}$ in Sea level, and $12.08 \pm 5.19 \mathrm{pg} / \mathrm{ml}$ in Ajloun. When the significance was tested using independent $\mathrm{T}$ test, there was a significant difference between the means of angiotensin II between Ajloun and Dead Sea $(\mathrm{p}=0.039)$. no other significant differences were observed between the study areas.

Table 2: Comparison between Angiotensin II Concentration ( $\mathrm{pg} / \mathrm{ml})$ in study áreas

\begin{tabular}{|l|l|l|l|l|}
\hline Target Area & Mean \pm std & Target Area & Mean \pm std & P value \\
\hline Dead Sea & $\mathbf{8 . 8 4} \pm \mathbf{4 . 6 5}$ & Sea level & $\mathbf{1 1 . 2 1} \pm \mathbf{6 . 0 5}$ & $\mathbf{0 . 1 2 9}$ \\
\hline Ajloun & $\mathbf{1 2 . 0 8} \pm \mathbf{5 . 1 9}$ & Dead Sea & $\mathbf{8 . 8 4} \pm \mathbf{4 . 6 5}$ & $\mathbf{0 . 0 3 9}$ \\
\hline Sea level & $\mathbf{1 1 . 2 1} \pm \mathbf{6 . 0 5}$ & Ajloun & $12.08 \pm \mathbf{5 . 1 9}$ & $\mathbf{0 . 5 7 1}$ \\
\hline
\end{tabular}

\section{Discussion}

Blood pressure is the main force for the hemodynamics that keeps continuous blood flow for all the body tissues which is essential for homeostasis. It is well known that blood pressure is regulated by two factors: first factor is the peripheral resistance which mainly depends on the elasticity of arterial system, mainly the arterioles, which determines the radius of these arteries and the influence of sympathetic activity through the baroreceptors during transient change of blood pressure. Also the level of the angiotensin hormone significantly can change the diameter of arterioles i.e. the peripheral resistance.

The second factor which regulates blood pressure is the blood volume which is mainly regulated by the level of rennin-angiotensin system that starts 
mainly from the kidney. So any condition that decreases or increases the level of blood pressure will be antagonized by changing the level of angiotensin.

The first line to change the radius is the vasoconstriction. It is the presence of oxygen that can cause vasoconstriction and hypoxia causes vasodilatation and this oxygen availability is different at different levels of altitude i.e. hypoxia at high altitude and high oxygen concentration at low altitude.

The results of the present study showed that among subjects who are within similar patterns of demographic characteristics, there were slight variations in blood pressure parameters. The age of participants was approximately 17 years, the age at which no hypertension is expected to occur to examine the effect of altitude on the angiotensin II level.

The concentration of angiotensin II, a hormone which is involved in the long-term regulation of blood pressure, was the highest at high altitude and it declined as we went down to the Dead Sea area ( $p$ value $\leq 0.05)$. This implies the effect of altitude on the level of angiotensin II. The highest level of angiotensin II was in Ajloun $12.08 \mathrm{pg} / \mathrm{ml}$ (the area with the highest altitude), and the lowest level was in the Dead sea $8.84 \mathrm{pg} / \mathrm{ml}$. The difference in means among the participants was statistically significant $(p=0.039)$. Up to the best knowledge of authors, this is the first study in Jordan that measures the level of angiotensin among population from various areas with different altitudes.

The data of our results agree with the study of Parati et al (2014) who reported increased blood pressure and angiotensin II among participants in high altitude areas and they confirmed their results through blocking of angiotensin receptor to maintain blood pressure.

\section{Conclusion}

The present study reflected changes in the level of angiotensin II with high altitude areas and this factor should be taken into account when antihypertensive drugs have to be selected.

\section{References:}

1. Ardaillou R (1997). Active fragments of angiotensin II: enzymatic pathways of synthesis and biological effects. Curr Opin Nephrol Hypertens, 6: 28-34.

2. Basso N, Terragno NA (2001). History about the discovery of the renin-angiotensin system. Hypertension 38 (6): 1246-9.

3. Berry C, Touyz R, Dominiczak AF, et al (2002). Angiotensin receptors: signaling, vascular pathophysiology, and interactions with ceramide. Am. J. Physiol. Heart Circ. Physiol. 281 (6): 2337-65. 
4. Carson P, Ziesche S, Johnson G, Cohn JN (1999). Racial differences in response to therapy for heart failure: analysis of the vasodilatorheart failure trials. Vasodilator-Heart Failure Trial Study Group. J Card Fail, 5:178 -187.

5. Gianfranco Parati, Grzegorz Bilo, Andrea Faini, Barbara Bilo, Miriam Revera, Andrea Giuliano, Carolina Lombardi, Gianluca Caldara, Francesca Gregorini, Katarzyna Styczkiewicz, Antonella Zambon, Alberto Piperno, Pietro Amedeo Modesti, Piergiuseppe Agostoni, Giuseppe Mancia (2014). Changes in $24 \mathrm{~h}$ ambulatory blood pressure and effects of angiotensin II receptor blockade duringacute and prolonged high-altitude exposure: a randomized clinical trial. European Heart Journal, doi:10.1093/eurheartj/ehu275

6. Guyton, Hall (2006). Textbook of Medical Physiology. Pennsylvania: Elsevier Saunders, (2006).

7. Hall JE (2003). Historical perspective of the renin-angiotensin system. Mol Biotechnol, 24 (1): 27- 39.

8. Lees KR, MacFadyen RJ, Doig JK, Reid JL. Al Guazzi MD, De Cesare N, Fiorentini C, Galli C, Moruzzi P, and Tamborini G (1993). The lesser circulation in patients with systemic hypertension. Circulation, 75: I56-I62.

9. Skurk T, Lee YM, Hauner H (2001). Angiotensin II and its metabolites stimulate PAI-1 protein release from human adipocytes in primary culture. Hypertension 37 (5): 1336-40.

10. Thomas M. Devlin (2006). Role of angiotensin in the extravascular system. Journal of human hypertension, 7 (2): 7-12. 